\title{
The Adoption of Circular Economy Principles in the Hotel Industry
}

\author{
Vanessa Gaffar $^{1 *}$, Agus Rahayu ${ }^{2}$, Lili Adi Wibowo ${ }^{3}$, Benny Tjahjono ${ }^{4}$ \\ ${ }^{1,2,3}$ Univesitas Pendidikan Indonesia, Jl. Dr. Setiabudhi No.229, 40154, Bandung, Indonesia \\ ${ }^{4}$ Coventry University, JA 317 Priory Street, CV1 5FB, Coventry, United Kingdom
}

\begin{abstract}
Objective - The aim of this study is to explore the awareness level of CE concept and to assess the adoption of the CE principles in the hotel industry.

Methodology/Technique - This study employed a qualitative method. In depth interviews were addressed to hotel managers. The hotels were chosen based on three categories: local, national chain and international chain hotel. Observation of evidence was also used to analyze information from existing condition.

Findings - The findings pointed out the awareness level of CE concept in each hotel categories. It also revealed how hotels adopt CE principles in their daily business routine and how they see the aforementioned concept as one of the factors that help to preserve the environment.

Novelty - This paper provides a clear look on the awareness level of CE concept and a new perspective of the adoption of CE principles in hotel industry.

Type of Paper: Empirical.

JEL Classification: M10, Z31

Keywords: Circular economy; awareness; principles; adoption; hotel industry

Reference to this paper should be made as follows: Gaffar, V; Rahayu, A; Wibowo, L.A Tjahjono, B. 2021. The Adoption of Circular Economy Principles in the Hotel Industry, J. Bus. Econ. Review, 6(1), 92-97. https://doi.org/10.35609/jber.2021.6.1(2)
\end{abstract}

\section{Introduction}

Circular economy (CE) is a concept that emphasizes the importance of product sustainability in one cycle before disposal or removal. MacArthur (2012) defines CE as an industrial system designed to be restorative and regenerative. $\mathrm{CE}$ is an important concept as it encourages companies to apply sustainable development in their business (Kirchherr et al., 2017; Ghisellini et al., 2016). The implementation of CE into business is in line with the Sustainable Development Goals (SDGs) that aim to provide a sustainable future for all. Currently, the world needs natural balance and environmental sustainability, requiring companies to have more eco-friendly business models. The implementation of CE, especially in industrial sectors, is expected to minimize sources input, waste, emission, and energy leakage by slowing, closing and narrowing materials and energy loops (Geissdoerfer, 2018).

\footnotetext{
*Paper Info: Revised: March 20, 2021

Accepted: June 30, 2021

* Corresponding author: Vanessa Gaffar

E-mail: vanessa@upi.edu

Affiliation: Faculty of Economics and Business Education, Universitas Pendidikan Indonesia, Indonesia
} 
A plethora of research on CE implementation in the production and manufacturing sectors has been conducted. For instance, Lieder and Rashid (2016) explain that the CE framework is supported by the principles, namely environment, resources, and economic benefits. They further suggest that supports from the stakeholders are vital to implementing a large-scale CE. Nevertheless, the research focusing on implementing CE in the service sector, especially in the hotel industry context, is relatively scarce. Pamfilie et al. (2018) suggest that CE's implementation in the hotel industry can create a business model that provides a sustainable experience for stakeholders. Pamfilie et al. (2018) view the implementation of CE from competitive advantage aspects, not from environmental and socio-cultural aspects. Besides, the research did not explain the connection between CE concepts, sustainability, and green concept. The seems to confirm Schneider (2015), stating that economic sustainability is considered more important than environmental and social aspects.

CE concept can also be implemented in service industry, including the hotel industry that, along with the tourism industry, contributes to the economy. The implementation of $\mathrm{CE}$ directly affects natural resource consumption and the environment around the hotel industry. When implementing CE, the hotel industry is encouraged to manage business sustainably, such as waste management and energy consumption, to minimize the negative impacts on the environment.

This research aims to fill the gap by investigating the adoption of $\mathrm{CE}$ in the hotel industry that could produce a significant amount of waste. This research is expected to raise hotel management awareness on the implementation of CE concepts and principles in the hotel industry.

\section{Literature Review}

Awareness is an element in the human automatization process involving intended or unintended actions (Chartrand, 2005). Liu and Bai (2014) state that awareness relates to individuals' knowledge and understanding of events. Morin (2011) specifically explains that self-awareness represents the capacity to be the center of attention. Individuals having self-awareness will identify, process, and store information of events actively. This research investigates the awareness of CE in the hotel industry.

CE shows the new concept on how to integrate economic activity and environmental wellbeing and focuses on the significance of the high value and quality material cycles in a new way (Murray, et.al, 2017; Korhonen et.al., 2018). CE replaces the end-of-life concept by having restoration, using renewable sources, eliminating hazardous non-recyclable chemicals that damage the biosphere, and designing superior materials, products, systems, as well as business models to reduce waste (MacArthur: 2012). Stahel dan Reday (1976) further illustrates that implementing CE in the industry reduces waste, adds more jobs, optimizes sources, and dematerializes the economy. CE is a regenerative system that minimizes inputs, wastes, emissions, as well as energy leakages by slowing, closing, and narrowing material and energy loops. To achieve the goals, the CE system designs, manages, fixes, reuses, reproduces, maintains, and recycles sustainably (Giessdoerfer et al., 2017; Kirchherr et al., 2017). Major global companies have already switched from the linear economy model to a circular economy model (Lewandowski, 2016)

The main aim of CE implementation is to mitigate the negative impact of industry on the environment and encourage economic growth through the development of the new business model (Kalmykova et al., 2018). By addressing environmental issues (Sauvé et al., 2016), CE aims to prolong the life of economic goods by closing the cycle of economy and ecology (Gregson et al., 2015; Haas et al., 2015).

Four components are required to develop CE: recirculation, minimization and sources recovery, multistage approach with significance to achieve sustainable development, and connection with society's innovation (Lieder dan Rashid, 2016). Moraga et al. (2019) put forward that to measure CE, life cycle mindset and gradual leveling, for instance, found in technology and cause-effect cycles, are required.

J. Bus. Econ. Review 6(1) 92 - 97 (2021) 
Moreover, Barnon et al. (2018) categorize CE into six principles, six attributes, and three enables. The principles of $\mathrm{CE}$ cover cascade orientation, waste elimination, economic optimization, maximization of retained value, environmental consciousness, and leakage minimization. Next, the attributes of CE consist of system thinking, circularity, built-in-resilience, collaborative network, shift to renewable energy, and optimization of change. Lastly, the enables of CE consist of technology-driven, market availability, and innovation. This study focuses on the six principles of CE.

\section{Research Methodology}

This qualitative research collects the data using an in-depth interview with nine hotel managers in Bandung, Indonesia. The interviews were based on research instruments regarding awareness and adoption of CE principles in the hotel industry. There are two local, four national, and three international hotels involved in this research. This research also employed observation to obtain empirical data from the field.

$\mathrm{CE}$ awareness was measured by questions about whether the hotel managers have heard CE concepts and the 3R (reduce-reuse-recycle) principle. The CE principle's implementation was measured by six questions: "Are items and products reused by the hotel?" "How is the waste management system of the hotel?" "What does the hotel do to optimize products and services to create economic resilience?" "How is the maintenance system of the hotel?" "How does the hotel preserve and mitigate damage to the environment?" and "What does the hotel do to maximize the utility of products?"

This research began with preliminary research on the relevant topic. Then, literature research, studying relevant sources and references about CE's awareness and adoption, was conducted before developing interview guidelines. After interviews with the hotel managers finished, the data were analyzed and interpreted.

\section{Results}

\subsection{CE Awareness}

The term CE generally was unfamiliar to the hotel managers, except for one hotel manager. In terms of 3R understanding, however, the hotel managers seem to understand the issue as they were aware of the connection between the $3 \mathrm{R}$ and green hotel concepts. Some hotel managers even suggested that they have practiced $3 \mathrm{R}$ and received awards for the implementation. The following is an explanation of the hotel manager regarding the award for $3 \mathrm{R}$ implementation.

"Yes... I've heard it so many times" (national chain hotel 02)

"...our hotel was awarded as the best four-star hotel for energy setting ... in Indonesia from the ministry of energy and mineral resources "(international chain hotel manager 02)

\subsection{CE Principles}

CE consists of six principles: cascade orientation, waste elimination, economic optimization, maximization of retained value, environmental consciousness, and leakage minimization. The principles are explained as follows.

The first principle of CE is cascade orientation; products are stored longer in circulation and turned into various products. Overall, the hotels have reused many of their products and facilities, although some are in the initial phase of implementing the principle. The following is the explanation of the hotel manager reusing their products and facilities.

"we only reuse straw .. yes it is reused... and then paper bag .. yes .. and laundry bag as well. We sometime reuse paper .. we use it both side .." (national chain hotel manager 02)

J. Bus. Econ. Review 6(1) 92 - 97 (2021) 
Some hotel managers do not reuse their products as they consider reused items less aesthetic or appealing.

"...when I did a presentation about using used materials for planting plants .. that's when the owner told me to buy something more proper ..." (nonchain hotel manager 02)

The second principle is waste elimination that emphasizes reducing or eliminating waste, starting from the initial design to the next phases. One of the hotels explained that they do not use single-use plastic entirely except for waste bins. They use biodegradable plastic even though the price is $25 \%$ higher than the regular ones.

The current regulation includes the standards for enterprises to manage their waste. The standards include the compulsion to have a wastewater treatment plant and trash sorting system, which have been met only by several hotels in this research.

“...our hotel doesn't have our own WWTP. but we manage the waste by doing direct sorting in every department" (nonchain hotel manager 01)

One hotel has its waste managed by the site management as the hotel is in the same building with an apartment and shopping center. The manager explained that the site management has a waste management system following the government standard and regulation.

"... we leave the waste management to the building management because there are also apartments and shopping mall in our location .." (international chain hotel manager 01)

The third principle is economic optimization indicated by a resilient and growing economy. In the COVID-19 pandemic, some hotels can address the increasing price and scarcity of ingredients issues by adjusting the price and menu while implementing the health protocol.

"no ... nothing ... in fact, the price from the supplier also seems to have dropped a bit ... because they don't dare to sell too much ..." (international chain hotel manager 02)

"....we monitor health protocol .. that is our commitment .. we also adjust our pricing strategy by improving the menu"(international chain hotel manager 03)

Some hotels can even maintain a high occupancy rate during the COVID-19 pandemic because they think creatively to survive in this challenging situation.

"so in doing a business we have to be creative ... I will do something that no one has it so others cannot copy it .. our occupancy rate is more than $85 \%$ while the others are under $20 \%$ "(national chain hotel manager 01)

The hotels have applied a regular standardized maintenance system, which indicates the implementation of the fifth CE principle, maximization of retained value. Maintenance is crucial to keep the equipment.

"maintenance is scheduled regularly .. if we don't do the maintenance, most equipment will be easily warry". (national chain hotel manager 04)

"we have a program called GCPM or general cleaning preventive maintenance ... to anticipate things to reduce energy consumption". (international chain hotel manager 03)

The next principle is environmental consciousness. In implementing this principle, some hotels use automatic sensors to preserve electricity and encourage hotel guests to save electricity and avoid excessive use by giving notices. Nevertheless, not all guests are aware of the importance of preserving the environment by saving electricity.

“... the awareness level of our guest on friendly environment is only $25-30 \% \ldots$ it does need education, yes, it needs education, continuous education. "(national chain hotel manager 01)

To mitigate the negative impact of hotels waste on the environment, some hotels have infiltration well to collect wastewater. Some hotels have begun reducing single-use plastic, such as plastic toothbrush, in the hotel rooms.

"... the water that is disposed becomes absorption and then it is sucked back into the well ..." (national chain hotel manager 03) 
"...our clean water waste can be reprocessed into water that can be used to water plants... the channel is different between clean waste and sewage wastewater"(international chain hotel manager 01)

The sixth principle is leakage minimization which emphasizes avoidance of loss to maximize products lifetime. For instance, the hotels should ensure waste does not leak to water lines and rooms are free from pollutants.

"We are using this humidifier in every room which is installed in the air conditioner to kill all bacteria and prevent of spreading.. " (national chain hotel 02)

\section{Discussion}

Overall, except for one manager, the hotel managements have not been familiar with the circular economy concept. However, all hotel managers are familiar with the green hotel concept, including the 3R (reducereuse-recycle) concept, and even have applied the concept daily. The hotel managers understanding of the green hotels indicates that the hotel managers have, in fact, implemented the CE concept despite not being familiar with the concept. The implementation of the CE concept varies among hotels. The local hotels tend to be driven by the owners' profit target. In some cases, aesthetic factors are prioritized over the reuse of old products for other purposes.

Hotel guests' awareness is also one crucial factor determining the implementation of the green concept. As the guest' satisfaction is the top priority, suggestions to save energy and reduce waste are not forceful. Guests can still use energy excessively without any consequences.

The CE is a holistic principle that requires a high involvement and commitment of stakeholders to implement this concept. Socialization is vital to raise the awareness of CE, especially in the hotel industry. If stakeholders in the hotel industry have a deep and holistic understanding of CE implementation, waste reduction and a sustainable environment can be achieved. Guest hotels should also be educated to raise their awareness and consistency in preserving the environment.

\section{Conclusion}

The CE awareness in the hotel industry is relatively low as the hotel managers are more familiar with the green hotel than the CE concept. Despite the low awareness, the hotel managers have had varied adoptions of the CE principles in their daily operations, depending on the hotels' category and chains. Some hotels have had a significant implementation of the concept, whereas other hotels are in the early implementation stage. Nevertheless, the trend indicates the hotels' awareness of green business and environmental preservation. This research recommends the hotel managers learn more about CE principles to improve their adoption effectiveness. The CE implementation in the hotel industry has become more urgent as it contributes a significant waste to the environment; thus, hotel managements must incorporate CE concepts into their business model. Moreover, hotel guests need to be educated about the importance of consistent environmental preservation.

This study focuses on the implementation of CE principles. Further research needs to broaden the study by including attributes and supporting factors of $\mathrm{CE}$ implementation into the investigation. Comparative research on the CE implementation of manufacturing and service sectors should also be conducted to provide a more holistic picture of the concept implementation. 


\section{Acknowledgement}

This paper was supported by Universitas Pendidikan Indonesia under the international research grant scheme 2020.

\section{References}

Bernon, M., Tjahjono, B., \& Ripanti, E. F. (2018). Aligning retail reverse logistics practice with circular economy values: an exploratory framework. Production Planning \& Control, 29(6), 483-497.

Chartrand, T. L. (2005). The role of conscious awareness in consumer behavior. Journal of Consumer Psychology, 15(3), 203-210.

Geissdoerfer, M., Savaget, P., Bocken, N. M., \& Hultink, E. J. (2017). The Circular Economy-A new sustainability paradigm?. Journal of cleaner production, 143, 757-768.

Ghisellini, P., Cialani, C., \& Ulgiati, S. (2016). A review on circular economy: the expected transition to a balanced interplay of environmental and economic systems. Journal of Cleaner production, 114, 11-32.

Gregson, N., Crang, M., Fuller, S., \& Holmes, H. (2015). Interrogating the circular economy: the moral economy of resource recovery in the EU. Economy and society, 44(2), 218-243.

Haas, W., Krausmann, F., Wiedenhofer, D., \& Heinz, M. (2015). How circular is the global economy?: An assessment of material flows, waste production, and recycling in the European Union and the world in 2005. Journal of industrial ecology, 19(5), 765-777.

Kalmykova, Y., Sadagopan, M., \& Rosado, L. (2018). Circular economy-From review of theories and practices to development of implementation tools. Resources, conservation and recycling, 135, 190-201.

Kirchherr, J., Reike, D., \& Hekkert, M. (2017). Conceptualizing the circular economy: An analysis of 114 definitions. Resources, conservation and recycling, 127, 221-232.

Korhonen, J., Honkasalo, A., \& Seppälä, J. (2018). Circular economy: the concept and its limitations. Ecological economics, 143, 37-46.

Lewandowski, M. (2016). Designing the business models for circular economy-Towards the conceptual framework. Sustainability, 8(1), 43.

Lieder, M., \& Rashid, A. (2016). Towards circular economy implementation: a comprehensive review in context of manufacturing industry. Journal of cleaner production, 115, 36-51.

Liu, Y., \& Bai, Y. (2014). An exploration of firms' awareness and behavior of developing circular economy: An empirical research in China. Resources, Conservation and Recycling, 87, 145-152.

MacArthur, E. (2013). Towards the circular economy. Journal of Industrial Ecology, 2, 23-44.

Moraga, G., Huysveld, S., Mathieux, F., Blengini, G. A., Alaerts, L., Van Acker, K.,. \& Dewulf, J. (2019). Circular economy indicators: What do they measure?. Resources, Conservation and Recycling, 146, 452-461.

Morin, A. (2011). Self-awareness part 1: Definition, measures, effects, functions, and antecedents. Social and personality psychology compass, 5(10), 807-823.

Murray, A., Skene, K., \& Haynes, K. (2017). The circular economy: an interdisciplinary exploration of the concept and application in a global context. Journal of business ethics, 140(3), 369-380.

Sauvé, S., Bernard, S., \& Sloan, P. (2016). Environmental sciences, sustainable development and circular economy: Alternative concepts for trans-disciplinary research. Environmental Development, 17, 48-56.

Schneider, A. (2015). Reflexivity in sustainability accounting and management: Transcending the economic focus of corporate sustainability. Journal of Business Ethics, 127(3), 525-536.

Stahel, W. (1976). Jobs for Tomorrow: The Potential for Substituting Manpower for Energy, Report to the Commission of the European Communities (now European Commission), Brussels. 